\title{
A TEORIA DISCURSIVA DE JÜRGEN HABERMAS: SUA RELAÇÃO INTERNA ENTRE DEMOCRACIA E DIREITOS FUNDAMENTAIS
}

\author{
Celso Hiroshi Iocohama ${ }^{1}$ \\ Horácio Monteschio ${ }^{2}$ \\ Juan Fernando Durán Alba ${ }^{3}$
}

\section{Resumo}

O presente trabalho enfoca a teoria discursiva de Jürgen Habermas como forma de reconstruir com legitimidade o Estado Democrático de Direito Constitucional. A atual estrutura normativa do direito apresenta-se como ineficaz e não acompanha o desenvolvimento complexo e dinâmico das sociedades pós-modernas. O sistema de direitos reflete crises de legitimidade na produção normativa, bem como na aplicação da justiça. As sociedades contemporâneas passam por inúmeras transformações e apresentam profundas contradições sociais, sendo que muitas vezes são instáveis e comandadas pelo capital. A teoria habermasiana procura solucionar a tensão existente entre democracia e direitos fundamentais, na busca por um ideal de democracia efetiva e compatível com o pluralismo das sociedades, procurando legitimar e efetivar os direitos fundamentais previstos na Constituição, proporcionando um real exercício desses direitos.

Palavras-chave: Direitos fundamentais; Democracia; Teoria Discursiva.

\footnotetext{
${ }^{1}$ Possui graduação em Direito pela Faculdade de Direito de Umuarama (1989), mestrado em Direito das Relações Sociais pela Universidade Estadual de Londrina (1996), doutorado em Direito pela Pontifícia Universidade Católica de São Paulo (2001), especialização em Docência do Ensino Superior pela Universidade Paranaense (2003) e doutorado em Educação pela Universidade de São Paulo (2011). Atualmente é professor titular de Direito Processual Civil I, da Universidade Paranaense, Campus Sede. Coordenador do Programa de Mestrado em Direito Processual e Cidadania da Unipar (desde 2008). É vice-presidente do Comitê de Ética em Pesquisa envolvendo Seres Humanos da UNIPAR.

${ }^{2}$ Doutor em Direito pela FADISP. Mestre em Direitos da Personalidade pela UNICESUMAR. Com Estágio em andamento de Pós-doutorado pelo UNICURITIBA. Com Estágio em andamento de Pós-doutorado em Direitos Humanos pelo Ius Gentium Conimbrigae da Faculdade de Direito da Universidade de Coimbra-Portugal. Professor de Direito Administrativo e Processo Administrativo do UNICURITIBA.

${ }^{3}$ Professor Titular de Direito Constitucional da Faculdad de Derecho/ Universidad de Valladolid. Licenciado y doctor en Derecho por la Universidad de Valladolid. Profesor Titular de Derecho Constitucional en la Facultad de Derecho de Valladolid. Abogado. Subdirector de la Revista General de Derecho Constitucional, editada por IustelPortal de Derecho, y miembro de su Consejo Editorial (desde 2016). Secretario de la Facultad de Derecho de Valladolid (2004-2008). Letrado de adscripción temporal en el Tribunal Constitucional (2008-2014). Vocal de la Junta Electoral de Castilla y León (2007-2008)
} 


\section{INTRODUÇÃO}

A partir do tema "A relação interna entre direitos fundamentais e democracia: um estudo à luz da teoria discursiva de Jürgen Habermas", e partindo do reconhecimento da importância dessa relação para o desenvolvimento do constitucionalismo pátrio, procura-se investigar como a teoria discursiva poderá contribuir para legitimar e efetivar os direitos fundamentais previstos na Constituição, proporcionando um real exercício desses direitos em sociedades cada vez mais pluralistas.

Jürgen Habermas é considerado um dos mais importantes filósofos da atualidade, suas ideias têm influenciado os estudiosos da filosofia constitucional. Através de sua teoria discursiva do direito, Habermas supera as visões liberais e comunitárias do direito, que não conseguem acompanhar uma sociedade multicultural, adotando uma concepção universalista sensível as diferenças.

A atual estrutura normativa do direito apresenta-se como ineficaz e não acompanha o desenvolvimento complexo e dinâmico das sociedades pós-modernas. O sistema de direitos reflete crises de legitimidade na produção normativa, bem como na aplicação da justiça. As sociedades contemporâneas passam por inúmeras transformações e apresentam profundas contradições sociais, sendo que muitas vezes são instáveis e comandadas pelo capital.

Ao superar os paradigmas liberal e republicano, Habermas, com sua teoria discursiva, desenvolve uma relação interna entre os direitos humanos e a soberania popular, possibilitando uma real coexistência entre autonomia privada e autonomia pública.

Seu modelo discursivo engloba tanto as concepções individuais de vida digna, como os valores compartilhados por identidades coletivas. Para tanto, defende que nenhuma das autonomias deve-se sobrepor a outra, eis que não são antagônicas, não havendo como optar por uma em detrimento da outra. Este seria, para ele, um dos desafios da democracia contemporânea, solucionar a tensão entre a necessidade de igual tratamento para todos e a proteção das identidades culturais. Tais concepções serão submetidas a um amplo debate público, através de regras procedimentais que permitem uma ampla argumentação, levando ao encontro de um consenso quanto à instituição de um direito legítimo.

A teoria discursiva de Habermas apresenta-se como uma solução para a legitimação e efetivação dos direitos fundamentais em sociedades pluralistas, bem como de toda a estrutura normativa do direito, superando a tensão existente entre democracia e direitos fundamentais. 
Neste sentido, somente é possível a produção de um direito legitimo se estiverem asseguradas, a participação ativa de todos os cidadãos, através de autonomia pública, bem como se estiverem garantidas as liberdades subjetivas de todos os indivíduos sem exceção, através da autonomia privada. Por conseguinte, direitos fundamentais e democracia se complementam.

A teoria discursiva ao superar a tensão existente entre legitimidade e legalidade poderá contribuir para a real efetivação dos direitos fundamentais a todos os cidadãos, contribuindo para a reconstrução do Direito ao interesse universal.

Tal teoria tem a pretensão de reformar todo o sistema de direito e assim levar a uma reconstrução legítima do Estado Democrático de Direito em sociedades pluralistas com inúmeras identidades culturais, valores diversos, várias concepções morais e religiosas.

Os direitos fundamentais configurados na Constituição, na visão de Habermas, apresentam um sentido deontológico, não sendo visto como valores, apresentando uma validade obrigatória e deverão ser protegidos efetivamente pelo Poder judiciário.

Resgatando o conceito de democracia radical e superando a tensão existente entre facticidade e validade, que é imanente ao direito, a teoria habermasiana objetiva um ideal de democracia que proporcione a efetivação dos direitos fundamentais e seja compatível com o pluralismo das sociedades pós-modernas.

A teoria democrático-procedimental habermasiana faz ainda, uma importante diferenciação entre discursos de aplicação e de justificação no âmbito dos sistemas político e jurídico. Levando assim a jurisdição constitucional ao importante papel de guardião da democracia e dos direitos fundamentais, que adquirem um caráter deontológico.

Habermas constrói ainda o conceito de 'patriotismo constitucional' configurando assim uma 'nação de cidadãos', autônomos, participativos e independentes, que vem a substituir o nacionalismo dos comunitaristas eis que, diante do pluralismo das sociedades não há como identificar comunidades com as mesmas identidades coletivas.

A teoria discursiva consegue que cidadãos estranhos entre si, tomem consciência que são ao mesmo tempo autores e destinatários de seus direitos, o que leva a uma participação ampla de toda a comunidade, onde todos são livres e iguais e têm respeitados os direitos fundamentais. Resgatando o conceito de legitimidade que surge da legalidade, tão importante ao desenvolvimento do direito.

Neste passo, surge um novo paradigma democrático-procedimental que influenciará todo o sistema de direitos, com o consequente desenvolvimento da teoria constitucional. 


\section{A TEORIA DISCURSIVA DE JÜRGEN HABERMAS}

As sociedades modernas têm como característica uma alta complexidade, há uma multiplicidade de valores culturais, religiosos e morais, com diversas concepções individuais do que seria uma vida digna. Neste diapasão, a única solução para o direito, como mecanismo regulador da sociedade, é buscar o consenso em meio a tanta diversidade. E a teoria discursiva habermasiana procura solucionar tais questões.

Para Habermas o multiculturalismo das sociedades traz uma discussão fundamental na interpretação do Estado Democrático de Direito, que traz inerente uma tensão entre o princípio do igual tratamento das pessoas e a busca pela proteção das várias identidades culturais de uma sociedade.

Nas palavras de Habermas, citado por Gisele Cittadino, a sociedade moderna "promove o individualismo nos projetos pessoais de vida e um pluralismo nas formas de vida coletiva". ${ }^{4}$

Nas sociedades pós-modernas, o capital e o poder adquirem uma força muito grande dentro do Estado exercendo uma grande influência na produção do direito. Somente com o conceito de democracia radical, concebida por Habermas, que pressupõe uma participação comunicativa e ativa, combinada com a representação política tradicional é possível superar os questionamentos quanto à legitimidade do direito e bem como sua adequação. Através desta teoria é possível a instituição de um direito legítimo, onde estarão garantidas as liberdades subjetivas conjuntamente com a ativa participação dos cidadãos.

Habermas leciona que o pluralismo das sociedades pós-modernas pode ser visto de duas maneiras, uma quando descrevemos as várias concepções de cada um sobre uma vida digna, visão liberal; e de outro foco, visão republicana, quando descrevemos as múltiplas identidades sociais e culturais dentro desta sociedade.

A teoria discursiva de Habermas surge como uma alternativa as visões liberais e comunitárias do direito que não conseguiram que o Direito atendesse ao interesse universal.

$\mathrm{Na}$ visão liberal do direito, numa sociedade democrática contemporânea existirão várias concepções individuais e distintas do que seja uma vida digna e, portanto, a autonomia privada deveria prevalecer sobre a autonomia pública. Já na visão republicana ou comunitarista, o direito do cidadão deveria ceder à vontade da maioria política, ou seja, o público prevaleceria sobre o privado.

\footnotetext{
${ }^{4}$ CITTADINO, Gisele. Pluralismo, Direito e Justiça Distributiva. Rio de Janeiro: Lumen Juris, 2004. p.90.
} 
Ao defender uma relação interna entre as autonomias pública e privada, a teoria discursiva de Habermas faz uma releitura das interpretações liberais e republicanas, conjugando-as de maneira que num Estado Democrático de Direito, os direito humanos e soberania popular desempenham papéis distintos mas ao mesmo tempo complementares.

Habermas afirma que, numa democracia a autonomia pública é importante, mas não há como nos afastarmos dos direitos fundamentais de cada cidadão, e somente seria possível conjugar essas duas autonomias através de sua teoria discursiva. Daí a importância da superação destes dois paradigmas que reflete no atual sistema de direitos uma profunda crise de legitimidade na produção normativa e ainda, um grande abismo na aplicação da justiça ao interesse universal.

A Democracia discursiva de Habermas, nos dizeres de Canotilho, não se assenta em valores universais do homem (numa perspectiva liberal) e nem na moral de uma comunidade específica (numa visão republicana), mas em regras de discussão cujo fim é proporcionar uma solução universal a questões problemáticas, morais e éticas da sociedade. ${ }^{5}$

Neste diapasão Habermas afirma:

\begin{abstract}
A co-originariedade da autonomia privada e pública somente se mostra, quando conseguimos decifrar o modelo da autolegislação através da teoria do discurso, que ensina serem os destinatários simultaneamente os autores de seus direitos. A substância dos direitos humanos insere-se, então, nas condições formais para a institucionalização jurídica desse tipo de formação discursiva da opinião e da vontade, na qual a soberania do povo assume figura jurídica. ${ }^{6}$
\end{abstract}

A legitimação do direito moderno é vista por Habermas como uma tensão entre direitos humanos e princípio da soberania do povo. Habermas constrói um modelo de autolegislação, através de sua teoria do discurso, onde os destinatários são ao mesmo tempo autores de seus direitos.

Autonomias pública e privada passam a ser entendidas como co-originárias. E ainda, Habermas entende que, em um nível pós-metafísico, a moral e o direito devem atuar de forma complementar. Assim os direitos humanos devem ser interpretados como jurídicos, não obstante o seu conteúdo moral.

Habermas formula uma teoria reconstrutiva que consegue obter um acordo racionalmente motivado, diante de um conflito normativo. Para tanto, a teoria discursiva

\footnotetext{
${ }^{5}$ CANOTILHO, J.J. Gomes. Direito Constitucional e Teoria da Constituição. 7. Ed. Coimbra: Almedina, 2003. p. 1417.

6 HAMERBAS, Jürgen. Direito e Democracia entre facticidade e validade I. 2. Ed. Rio de Janeiro: Biblioteca Tempo Universitário 101, 2003. p. 139.
} 
habermasiana permite uma situação ideal de diálogo, onde todos os participantes têm acesso e prevalece à força do melhor argumento. Assim Habermas idealiza um projeto de construção de um espaço público, onde estão asseguradas a democracia, através de uma participação imparcial, longe de coação, coerção e qualquer influência externa.

A teoria habermasiana tenta solucionar os problemas enfrentados pelo direito nas sociedades modernas, e um destes problemas é denominado por ele como "colonização do mundo da vida", onde os sistemas econômico e político-administrativo, que integram a sociedade ampliam seu espaço de ação, passando a "colonizar" as formas espontâneas de reprodução social e, consequentemente toda a produção normativa, atingindo o direito como um todo.

Nesta passo, Habermas afirma que o mundo da vida é composto por uma esfera privada e uma esfera pública. A esfera privada se relaciona como o sistema econômico, e quando há uma colonização do mundo da vida, está esfera é dominada pelo capital. E o mesmo pode acontecer com a esfera pública que passa a ser burocratizada, invadindo os processos de legitimação democrática.

Quando há uma colonização do mundo da vida, o direito que é fonte integradora e legitimadora do processo democrático e garantidor dos direitos fundamentais, passa a servir aos sistemas econômicos e de poder. Por isso, é que Habermas procura resgatar a legitimidade do direito e a formação democrática da legislação, eis que somente com a efetiva participação dos cidadãos consegue-se legitimar e reconstruir o Estado democrático-constitucional de direito.

Nos dizeres do próprio Habermas:

\footnotetext{
Penso que as sociedades complexas contemporâneas se integram até certo ponto através de três veículos ou mecanismos. $\mathrm{O}$ 'dinheiro' enquanto veículo está, por assim dizer, institucionalizado no mercado; o 'poder' enquanto veículo está institucionalizado nas organizações; e a 'solidariedade' é gerada pelas normas, valores e pela comunicação. ${ }^{7}$
}

Habermas não tem a pretensão de construir uma teoria que elimine toda a colonização do mundo da vida, mas acredita que a mantença de um espaço público baseado na reciprocidade e respeito mútuo, poderá estabelecer normas que permitam que a dominação seja enfrentada, criticada e cerceada.

\footnotetext{
${ }^{7}$ HABERMAS, op. cit. p.38.
} 
Através de uma esfera pública ativa, produtora de um direito legítimo e democrático, que regenera todo o sistema político, é que haverá o impedimento da colonização do mundo da vida.

É preciso que os cidadãos efetivamente participem da produção normativa através de um espaço público, onde esteja assegurada a igualdade e liberdade a todos. Somente assim pode-se obter a legitimidade do direito. As inúmeras formas de vida nas atuais sociedades somente permitem que através de um consenso seja regulada a vida dos cidadãos, que são ao mesmo tempo autores e destinatário de suas normas.

Cidadãos participativos que veem legitimidade no direito, serão capazes de regular suas relações através da teoria discursiva, que mantém assegurados os direitos fundamentais, que nesta teoria adquirem um caráter deontológico.

Além disso, Habermas parte do pressuposto que um traço fundamental das sociedades atuais é a capacidade de auto-reflexão dos indivíduos. A hermenêutica, em Habermas, conforme salientado por Cittadino, designa o espaço de auto-reflexão e crítica, enquanto que a pragmática inclui o território discursivo cujo núcleo central é o entendimento. E será através da conjunção da hermenêutica e da pragmática que se constituirá a formação racional da vontade. ${ }^{8}$

A formação racional da vontade pressupõe um espaço público com uma ampla prática argumentativa, onde todos os participantes procuram estabelecer um consenso. Através deste amplo debate, que leva em conta as concepções individuais e também os valores de toda sociedade, estabelecer-se-ão as normas que terão como destinatários seus próprios autores. Reconstruindo, assim, nos dizeres de Habermas: "um sistema de direitos que tem origem na associação voluntária de cidadãos que legitimamente elaboram o seu direito positivo". 9

Habermas sustenta que a função do direito é gerar integração social. O direito portanto, executa sua função de integração a partir das seguintes ações:

(1) regenera o código dos sistemas políticos e econômicos; (2) viabiliza a comunicação entre os sistemas e o mundo da vida; (3) na forma de um sistema de ação forma o meio pelo qual as instituições do direito se reproduzem junto com as: (3.1) tradições jurídicas compartilhadas intersubjetivamente; (3.2) capacidade subjetivas de interpretação do direito no âmbito do mundo da vida. Dessa forma, o direito realiza a integração social e dele participam todas as comunicações que por ele se orientam. ${ }^{10}$

\footnotetext{
${ }^{8}$ CITTADINO, op. cit. 93.

${ }^{9}$ HABERMAS, op. cit. p.213.

${ }^{10}$ SAAVEDRA, op. cit. 126.
} 
A ética discursiva pretende compensar a perda da eticidade das sociedades democráticas contemporâneas, onde o poder econômico exerce grande controle e influência. Enfrentando, através de uma racionalidade prática, contextualizando as normas morais, através da instauração de um processo democrático, submetendo a um processo de justificação as normas e instituições das sociedades atuais.

Tendo em vista o multipluralismo das sociedades Habermas defende uma posição que consiga conjugar o reconhecimento das diferenças, com a inclusão do cidadão na comunidade política, e a valorização da autonomia individual, encontrando o equilíbrio entre igualdade e diversidade.

Habermas acredita que os princípios de justiça são institucionalizados por uma constituição democrática e que a luta pela implementação dos princípios específicos de justiça distributiva e as controvérsias que envolvem esses princípios devem ser submetidas a uma avaliação democrática. Nesta esteira, afirma que " Os discursos são como máquinas de lavar: filtram aquilo que é racionalmente aceitável para todos". ${ }^{11}$

\subsection{DEMOCRACIA E DIREITOS FUNDAMENTAIS}

A teoria discursiva pretende concretizar procedimentalmente os direitos fundamentais através de "um paradigma de racionalidade do entendimento que leve ao cumprimento das condições de reconhecimento intersubjetivo da validez normativa, a qual consiste e possibilita a aceitabilidade racional". ${ }^{12}$

Ao desenvolver uma interpretação dos direitos fundamentais à luz da teoria do discurso, Habermas tem a pretensão esclarecer o nexo interno entre direitos fundamentais e soberania do povo e também solucionar o paradoxo da legitimidade que surge da legalidade.

Habermas acredita que a Constituição ao configurar um sistema de direitos fundamentais, tem a função de contextualizar princípios universalistas e transformá-los numa base comum a todos os cidadãos. A tese habermasiana atribui um sentido deontológico de validades às normas e princípios constitucionais.

E nos dizeres de Habermas:

\footnotetext{
${ }^{11}$ HABERMAS, op. cit.63.

${ }^{12}$ DUARTE, op. cit 250.
} 
"A idéia dos direitos humanos e a da soberania do povo determinam até hoje a autocompreensão normativa de Estados de direito democráticos. A história de teoria é um componente necessário, um reflexo da tensão entre facticidade e validade, entre positividade do direito e a legitimidade pretendida por ele, latentes no próprio direito". 13

Nesta esteira, também são as lições de Canotilho, quando afirma que, o Estado de Direito Democrático-Constitucional assenta-se na indispensabilidade da democracia, e ainda: “ a articulação do processo democrático com o processo de institucionalização de garantias fundamentais conduzirá sempre à análise da complexidade do estado de direito democráticoconstitucional". ${ }^{14}$

O direito na era pós-moderna deverá enfrentar questões complexas que lhe são apresentadas e ainda, assegurar um melhor relacionamento do homem com o mundo, bem como com seus pares. Conferindo legitimidade ao sistema normativo e assegurando os direitos fundamentais a todos.

Habermas separa as questões valorativas das questões de justiça, a ética discursiva deve assegurar que determinados valores estejam assegurados, quais sejam os direitos fundamentais.

Habermas com sua teoria discursiva se propõe a isso, e nos dizeres de Canotilho enuncia a seguinte tese:

"a gênese lógica dos direitos fundamentais constitui um processo circular, no qual o código do direito e o mecanismo dirigido a constituir direito legítimo, ou seja, os princípio democrático, se constituem co-originariamente. Algumas categorias de direitos fundamentais são mesmo princípios "vinculativos" do poder constituinte. Habermas distingue cinco categorias de direitos fundamentais: (1) direitos fundamentais resultantes do desenvolvimento politicamente autônomo do direito ao mais amplo leque de liberdades subjectivas de acção iguais para todos; (2) direitos fundamentais resultantes do desenvolvimento politicamente autónomo do estatuto de membro numa associação livre de " sócios" jurídicos; (3) direitos fundamentais que resultam de modo imediato da exigibilidade dos direitos e do desenvolvimento, politicamente autónomo, da protecção jurídica individual; (4) direitos fundamentais a uma participação em condições de igualdade nos processos de formação da opinião e da vontade no âmbito do qual os cidadãos exercem a sua autonomia política e através do qual instauram o direito legítimo; (5) os direitos fundamentais à garantia das condições de vida a nível técnico, social e ecológico na medida em que isso se possa considerar necessário, em determinadas circunstâncias, à existência de

\footnotetext{
${ }^{13}$ HABERMAS, op. cit. 128.

${ }^{14}$ CANOTILHO, op. cit. 1334.
} 
uma igualdade de oportunidades para o exercício dos direitos cívicos enumerados de (1) a (4).”( CANOTILHO, 1404)

Ressalte-se ainda que, os direitos fundamentais que integram as constituições democráticas são um exemplo de moralidade universalista, eis que são princípios universais. Os direitos fundamentais são essenciais quando se fala em legitimidade do direito, pois só haverá legitimidade num sistema jurídico se nele estiverem positivados tais direitos.

E assim, numa visão habermasiana, só haverá uma verdadeira democracia quando houver legitimidade do direito, que pressupõe garantia das liberdades subjetivas conjugada com a ativa participação dos cidadãos. Em outras palavras, numa sociedade verdadeiramente democrática deverá haver liberdade de discurso com garantia de direitos fundamentais.

Habermas assevera que o princípio da democracia resulta da interligação existente entre o princípio do discurso e a forma jurídica, o que denomina de 'uma gênese lógica de direitos'. Afirma ainda que o princípio da democracia só pode aparecer como núcleo de um sistema de direitos, formando um processo circular, no qual o código do direito e o mecanismo para a produção de direito legítimo, portanto o princípio da democracia se constituem de modo co-originário. ( HABERMAS, 158)

Neste diapasão, Habermas leciona que :

\begin{abstract}
"Uma soberania popular interligada internamente com as liberdades subjetivas, entrelaça-se, por seu turno, com o poder politicamente organizado, de modo a que o princípio 'todo o poder político parte do povo' vai ser concretizado através dos procedimentos e pressupostos comunicativos de uma formação institucionalmente diferenciada da opinião e da vontade. No Estado de direito delineado pela teoria do discurso, a soberania do povo não se encarna mais numa reunião de cidadãos autônomos facilmente identificáveis. Ela se retira para os círculos de comunicação de foros e corporações, de certa forma destituídos de sujeito. Somente nesta forma anônima, o seu poder comunicativamente diluído pode ligar o poder administrativo do aparelho estatal à vontade dos cidadãos". ${ }^{15}$
\end{abstract}

Habermas enxerga no sistema de direitos, uma tensão entre a positividade e a legitimidade do direito, assim como àquela entre autonomia pública e privada. E ao ampliar a ideia do Estado de direito, abre-se uma nova perspectiva, pois com a produção do direito, passa-se a uma dominação organizada juridicamente, cujo exercício deve ficar ligado a um direito legítimo.

${ }^{15}$ HABERMAS, 173. 
A teoria discursiva não tem a pretensão de neutralidade, mas sim um ideal de imparcialidade que deverá ser atingido tendo como fio condutor a garantia da liberdade e igualdade na argumentação. Nos dizeres de Écio Duarte isso fica demonstrado " pelo caráter universalista da concepção teórico-discursiva da racionalidade prática. No conteúdo da tese habermasiana a legitimidade do direito se vincula, assim, à aceitação universal”.

Habermas acredita que o direito deve desempenhar um papel de mediador entre a facticidade da política e da economia e a pretensão de validade normativa da moral. Eis que a tensão imanente ao direito entre facticidade e validade manifesta-se como tensão entre o princípio da segurança jurídica e a pretensão de retitude.

Habermas afirma que “o poder político só pode desenvolver-se através de um código jurídico institucionalizado na forma de direitos fundamentais"

Ressalte-se, ainda que, quando os direitos fundamentais são assegurados em uma Constituição através de um procedimento democrático-deliberativo, eles passam a ser normas de caráter obrigatório e não estão sujeitos a relações de preferência, como os valores, como afirmam os comunitários.

\subsection{O SISTEMA DE DIREITOS}

Nos ensinamentos de Habermas, o princípio da democracia aparece como núcleo de um sistema de direitos, um sistema que será obtido a partir da interligação entre o princípio do discurso e a forma jurídica.

Esse sistema de direitos será plenamente reconhecido pelos cidadãos, eis que serão seus autores, e também destinatários. O sistema regulará a vida em comum por meio do direito posto e, conterá as condições necessárias para a implementação de processos democráticos de discussão, sendo construído a partir de um modelo de democracia procedimental.

Explicitando melhor, para Habermas, o sistema jurídico terá como base a faticidade e a validade, ou seja, a coerção de um direito legalmente constituído e a força resultante de um entendimento racionalmente motivado.

O direito posto e seus mecanismos de coerção, para Habermas, deverão ser submetidos a um processo legislativo democrático a fim de se obter a legitimidade do direito.

Nesta visão, somente através da teoria discursiva com sua ação comunicativa será capaz de "legislar" com legitimidade irradiando assim para toda a comunidade. Habermas preleciona que: 


\begin{abstract}
"Argumentos em prol da legitimidade do direito devem ser compatíveis com os princípios morais da justiça e da solidariedade universal - sob pena de dissonâncias cognitivas- bem como com os princípios éticos de uma conduta de vida autoresponsável, projetada conscientemente, tanto de indivíduos, como de coletividades." 16
\end{abstract}

Assim, superam-se os paradigmas do direito liberal e do bem-estar, através de um paradigma procedimental do direito, que estabelece a relação interna entre autonomia pública e privada, associando o direito legítimo à democracia.

Nas lições de Gisele Cittadino, o paradigma procedimental do direito assegura a todos o direito de participar da interpretação da Constituição. ${ }^{17}$

A tese habermasiana apresenta uma importante contribuição na teoria do direito, eis que possibilita a aplicação de um direito mais flexível, exigência de sociedades pluralistas e muitas vezes até contraditórias, onde a função reguladora do direito e sua legitimação são sempre questionadas e confrontadas.

Habermas acredita que as Constituições modernas ao configurarem um sistema de direitos que contemplem os direitos fundamentais, têm a função de contextualizar tais princípios como universais e transformá-los numa base comum a todos os cidadãos. Daí a importância de atribuir-se um sentido deontológico de validade as normas e princípios constitucionais como já asseverou Habermas.

O sistema de direitos não deve ignorar, segundo lições de Luiz Bernardo Araújo:

\footnotetext{
“a conexão interna entre a autonomia pública e autonomia privada, satisfazendo os critérios morais do universalismo igualitário, que exige o respeito por todos, e o critério ético do individualismo, segundo a qual cada pessoa tem o direito de conduzir sua vida de acordo com suas próprias preferências e convicções". ( ARAÚJO, 125)
}

Habermas defende que o princípio da democracia está subordinado a um sistema de direitos, que se constituem de modo co-originário. Por isso, como já afirmado anteriormente, o princípio da democracia só pode aparecer como núcleo de um sistema de direitos.

Uma teoria do direito, apoiada no princípio do discurso, torna possível introduzir um paradigma procedimental do direito que permite ultrapassar superar os modelos sociais do direito formal burguês e do Estado social. Neste sentido Écio Duarte, preleciona:

\footnotetext{
${ }^{16}$ HABERMAS, 2003, op. cit. p. 133.

${ }^{17}$ CITTADINO, op. cit. 2004.
} 
“O paradigma do Estado democrático de direito impõe uma redefinição do papel da própria teoria do direito constitucional(...). Acreditamos que a estruturação ideal de uma matriz hermenêutico-argumentativa, composta pelos princípios éticodiscursivos, poderá imprimir o paradigma metodológico da razão prática no discurso constitucional como forma de 'oxigenar' a aceitação do programa normativopolítico da própria Constituição”.(DUARTE, 247)

Neste sentido, a democracia surgida a partir da ética discursiva não se reduz apenas a dimensão política, mas compreende, também, uma dimensão substancial através dos princípios constitucionais e, especialmente, pelos direitos fundamentais, que se vinculam de igual modo ao conteúdo das leis. Nesta esteira, Écio Duarte acrescenta que: “ devem complementar-se: exigências de racionalidade( regras procedimentais do discurso prático ideal) com requerimento de justiça social ( função normativa do princípio do discurso), alcançados quando a argumentação jurídico-constitucional encontra-se discursivamente validada por valores ético-sociais”. (DUARTE, 248)

Embora distintos, os princípios da moral e da democracia não estão ordenados hierarquicamente. Para Habermas, ao contrário, eles são complementares, de tal modo que a legitimidade jurídica não pode ser assimilada à validade moral, como no caso do jusnaturalismo, e tampouco o direito deve estar completamente separado da moral, como defende o positivismo. O direito é compreendido como um complemento funcional da moralidade pós-tradicional.

Defendendo que a ética discursiva tem como objetivo, tendo em vista um conflito normativo, o encontro de um acordo racionalmente motivado, recorre assim, para obtenção deste acordo a um diálogo amplo e sem restrições, onde prevalecerá o melhor argumento, que deverá atender as exigências de não limitação; não violência, ou seja, não haverá pressões. Impende ressaltar que é importante também a seriedade na participação, tendo em vista o objetivo fundamental de buscar cooperativamente um denominador comum, conjugando assim o ideal da democracia com as demandas legítimas de indivíduos e grupos.

O cerne de uma compreensão genuinamente procedimental de democracia, nos termos de Habermas "consiste precisamente no fato de que o processo democrático institucionaliza discursos e negociações, com o auxílio de formas de comunicação que devem fundamentar a suposição da racionalidade para todos os resultados obtidos conforme o processo". ${ }^{18}$

Neste diapasão salienta:

\footnotetext{
${ }^{18}$ HABERMAS, 158.
} 
"Somente a normatização politicamente autônoma permite aos destinatários do direito uma compreensão correta da ordem jurídica em geral. Pois o direito legítimo só se coaduna com um tipo de coerção jurídica que salvaguarda os motivos racionais para a obediência do direito. Nos dizeres de Habermas: "Normas jurídicas devem poder ser seguidas com discernimento". (HABERMAS, 158)

Para Habermas, citado por Saavedra, a constituição de um código do poder significa que "um sistema administrativo se orienta por autorização que permitem decisões coletivamente obrigatórias(...) O código do poder ligado ao poder comunicativo deve manterse longe das pressões do poder social a fim de não valorizar interesses privilegiados. $\mathrm{Na}$ formação discursivamente estruturada de opinião e da vontade de um legislador político há uma interligação entre normatização jurídica e formação do poder comunicativo". ${ }^{19}$

Habermas desenvolve um modelo procedimental de formação política racional da vontade que se apresenta como uma rede de discussões e negociações que tem por fim regenerar o sistema político através do poder comunicativo.

Neste passo, uma lei constitucional não pode ser completamente vazia do ponto de vista substantivo, uma excessiva substantivação do texto constitucional implicará em sérios riscos a sua força normativa. Nas palavras de Canotilho, "o facto de dizermos que deve haver uma constituição procedimental não significa que o texto se reduza a um esqueleto normativo, sem sustância, sem verbo, sem espírito, sem matéria”. ${ }^{20}$

As sociedades pós-modernas podem ser definidas como pós-convencionais e são caracterizadas pela multiplicidade de identidades coletivas, culturais, sociais, étnicas e também das inúmeras concepções individuais sobre uma vida digna, que são próprias do pluralismo.

Em um mundo tão pluralizado é impossível encontrar identidades compartilhadas em face disto é preciso que a cidadania democrática se transforme numa espécie de força integradora da sociedade. Diante desta necessidade Habermas cria o que chama de "patriotismo constitucional" que seria uma modalidade de conformação de uma identidade coletiva, que viria em substituição ao nacionalismo, incompatível as sociedades contemporâneas. "O patriotismo constitucional deve se ancorar em uma concepção de cidadania democrática capaz de gerar solidariedade entre estranhos.”

O patriotismo constitucional idealizado por Habermas não se confunde com o nacionalismo do pensamento comunitário que pressupõe uma identificação de valores comuns próprios de uma comunidade histórica. Como atualmente não há essa identificação valorativa

${ }^{20}$ COUTINHO, 21. 
nas comunidades, há que se substituir a "nação de cultura" por uma "nação de cidadãos", que encontraram sua identidade na pratica da cidadania ativa, com o exercício dos direitos de participação e comunicação.

Será através da concepção do patriotismo constitucional de Habermas que a solidariedade configura-se como forma de integração social, vinculando formas de vida individuais com os direitos humanos que são normas universalmente válidas. E daí surge a uma nova tensão entre formas de vida individuais e formas de vida compartilhadas que só poderão ser ajustadas através de um amplo debate público, onde todos os cidadãos participam efetivamente.

\section{RECONSTRUINDO O ESTADO DEMOCRÁTICO DE DIREITO}

Na teoria discursiva da democracia habermasiana os elementos da normatização constitucional e do processo político de formação de opinião e da vontade são assumidos sob um novo aspecto.

Nesta esteira são as afirmações de Canotilho "A existência de um espaço político público "desconfiado, móvel, vigilante e bem informado" que dinamize iniciativas populares, introduza alternativas nas escolhas políticas, domestique o poder dos media, imponha justificações rigorosas aos actos políticos, defenda o espaço dos cidadãos perante os privilégios neocorporativos, é hoje um controlo insubstituível nos estados constitucionais. ( CANOTILHO,1455)

A teoria de Habermas consegue levar ao Estado Constitucional Democrático, eis que a mesma atende duas exigências fundamentais ao conteúdo e à estrutura do sistema jurídico, segundo Robert Alexy: direitos fundamentais e democracia. (Alexy, 33)

Habermas leciona que: “A idéia do Estado de direito pode ser interpretada então como a exigência de ligar o sistema administrativo, comando pelo código do poder, ao poder comunicativo, estatuidor do direito, e de mantê-lo longe das influências do poder social, portanto, da implantação fática de interesses privilegiados. ${ }^{21}$

E, além disso, o constitucionalismo democrático necessita da atuação de um judiciário comprometido com a democracia, garantidor de condições para o exercício da cidadania. Uma jurisdição que leve em conta as desigualdades sociais, bem como o

\footnotetext{
${ }^{21}$ HABERMAS, 190.
} 
pluralismo de identidades culturais e individuais, sem, no entanto, ser um substituto para a cidadania que deve garantir.

Os paradigmas anteriores, como já citado anteriormente, não conseguiram que o direito atendesse ao interesse universal. Podendo-se observar dentro destes paradigmas, duas visões por parte do judiciário, em uma o judiciário, em respeito ao princípio da separação dos poderes, não resolve questões políticas, apresentando um papel apenas secundário, garantidor apenas do mínimo. E outra visão, em que a política é judicializada, atribui-se ao poder judiciário o papel de "tutor" da política, atribuindo valores a uma determinada comunidade.

$\mathrm{Na}$ teoria discursiva o direito, em sua função instrumental, legitima a ação do Estado, que passa a ter competência de tomar decisões. Ou seja, ao atribuir uma forma ao poder político, o direito atua como organizador desse poder, que institucionaliza o direito e reforça suas decisões. Nesta visão não se pode limitar o direito constitucional ao judiciário, pois o direito constitucional é a ligação do político com o jurídico.

O principal órgão que atua em defesa desta esfera pública é o tribunal constitucional que é visto como um "guardião da democracia", que tem como principal instrumento os direitos fundamentais. E nas lições de Saavedra, será a partir dos discursos de aplicação dos direitos fundamentais que o tribunal protege a esfera pública impedindo sua contaminação e colonização pelos meios sistêmicos( dinheiro e poder ). (SAAVEDRA, 135)

O judiciário é, na visão de Habermas, fundamental para o surgimento de uma cidadania ativa, pois é ele que agirá em defesa do 'princípio da democracia' e dos 'direitos fundamentais'.

No âmbito da jurisdição a tensão existente no direito entre facticidade e validade se manifesta como uma tensão entre os princípios da segurança jurídica e o princípio da retitude das decisões. A jurisdição deverá conjugar, na aplicação de suas decisões, simultaneamente, a garantia de correção e de segurança jurídica.

Na teoria habermasiana só é possível a aplicação de princípios de aplicação do direito quando eles são inseridos como critérios de decisão dentro de um processo democrático de formação da legislação. Tais princípios adquirem um caráter deontológico, sendo um exemplo disto a constitucionalização dos direitos fundamentais. Portanto, não se admite nesta teoria a inclusão de novos princípios no processo de aplicação do direito.

O judiciário deve contar com a ajuda dos cidadãos, resgatando-se assim a "sociedade aberta dos intérpretes da Constituição", pois a correção dos argumentos na teoria procedimentalista habermasiana traduz-se em "aceitabilidade racional", eis que a resposta correta não pode ser explicada por intermédio de uma teoria do direito, por mais desenvolvida 
que ela seja. Portanto, a resposta correta terá como subsídio a prática da argumentação, que tem como objetivo a busca pelo consenso, com assentimento de todos os participantes, num ambiente livre de pressões.

Habermas acredita que, se os tribunais constitucionais, puderem se guiar pela idéia de concretização de valores materiais, poderão assumir todas as razões em caso de colisão, transformando-se consequentemente em um tribunal autoritário e irracional, eis que qualquer tese poderá ser utilizada como argumento.

Já na teoria discursiva, onde os discursos são divididos em discursos de aplicação e justificação, no discurso jurídico há uma compreensão deontológica das normas e princípios do direito, portanto, somente atuarão com base em discursos de aplicação. O tribunal constitucional deve levar a sério o sentido deontológico dos direitos fundamentais, não os sujeitando a uma análise de custos e vantagens.

Há inúmeras críticas a teoria discursiva de Habermas, que de um lado afirmam que a mesma subestimaria a importância das identidades culturais e por outro, que não reconhece com profundidade os valores nas sociedades pluralistas contemporâneas.

Os cidadãos de um Estado devem lutar por sua cidadania, num espaço que promova a discussão e onde haja reconhecimento recíproco de que todos devem fazer parte do processo democrático.

A teoria habermasiana atende as exigências de racionalidade com requerimentos de justiça social, eis que se encontra fundamentada em valores ético-sociais, além de estabelecer materialmente a efetivação dos direitos fundamentais.

\section{CONCLUSÃO}

Com sua teoria discursiva do direito, Habermas supera um dos grandes desafios da democracia contemporânea, qual seja a conjugação da autonomia privada com a pública, reconstruindo a relação do direito legítimo com o poder político, através de uma relação interna entre direitos fundamentais e democracia.

Ao reconstruir esta relação interna pretende ainda, dar uma forma jurídica e legítima ao poder político. Pugnando por um sistema que contemple os direitos fundamentais, que deverão ser obrigatoriamente atribuídos mutuamente pelos cidadãos, de modo à regular a sua convivência com os meios legítimos do direito posto.

Será através de um amplo debate público, onde serão levadas em conta as concepções individuais e também os valores de toda sociedade, que se estabelecerão normas 
legítimas, eis que elas terão como destinatários seus próprios autores. Tal debate assegura que o sistema de direitos será formado pela vontade de cidadãos plenamente autônomos, capazes de auto-realização e de autodeterminação.

Cidadãos participativos que veem legitimidade no direito, serão capazes de regular suas relações através da teoria discursiva, que mantém assegurados os direitos fundamentais, que nesta teoria adquirem um caráter deontológico.

Os paradigmas liberal e social do direito não conseguiram lidar com as características do direito moderno e das sociedades, com a complexidade de questões jurídicas que envolvem uma concepção acerca da legitimidade e da efetividade constitucionais.

A teoria discursiva consegue que cidadãos estranhos entre si, tomem consciência que são ao mesmo tempo autores e destinatários de seus direitos, o que leva a uma participação ampla de toda a comunidade, onde todos são livres e iguais e têm respeitados os direitos fundamentais. Resgatando o conceito de legitimidade que surge da legalidade, tão importante ao desenvolvimento do direito.

Tendo em vista o multipluralismo das sociedades Habermas defende uma posição que consiga conjugar o reconhecimento das diferenças, com a inclusão do cidadão na comunidade política, e a valorização da autonomia individual, encontrando o equilíbrio entre igualdade e diversidade.

A ética discursiva pretende compensar a perda da eticidade das sociedades democráticas contemporâneas, onde o poder econômico exerce grande controle e influência. Enfrentando, através de uma racionalidade prática, contextualizando as normas morais, através da instauração de um processo democrático, submetendo a um processo de justificação as normas e instituições das sociedades atuais.

Neste passo, surge um novo paradigma democrático-procedimental que influenciará todo o sistema de direitos, com o consequente desenvolvimento da teoria constitucional.

A tese habermasiana apresenta uma importante contribuição na teoria do direito, eis que possibilita a aplicação de um direito mais flexível, exigência de sociedades pluralistas e muitas vezes até contraditórias, onde a função reguladora do direito e sua legitimação são sempre questionadas e confrontadas.

Habermas acredita que as Constituições modernas ao configurarem um sistema de direitos que contemplem os direitos fundamentais, têm a função de contextualizar tais princípios como universais e transformá-los numa base comum a todos os cidadãos. Daí a importância de atribuir-se um sentido deontológico de validade as normas e princípios constitucionais como já asseverou Habermas. 
Com estas idéias Habermas idealiza um projeto de construção de um espaço público, onde estaria assegurado o respeito, a reciprocidade e a imparcialidade, através das regras de um procedimento discursivo, que levam em conta as concepções individuais e os valores sociais, onde estaria assegurada uma moralidade mínima.

Habermas acredita que os princípios de justiça são institucionalizados por uma constituição democrática e que a luta pela implementação dos princípios específicos de justiça distributiva e as controvérsias que envolvem esses princípios devem ser submetidas a uma avaliação democrática.

E assim, numa visão habermasiana, só haverá uma verdadeira democracia quando houver legitimidade do direito, que pressupõe garantia das liberdades subjetivas conjugada com a ativa participação dos cidadãos. Em outras palavras, numa sociedade verdadeiramente democrática deverá haver liberdade de discurso com garantia de direitos fundamentais.

Num verdadeiro Estado Democrático de Direito, os direitos fundamentais devem estar garantidos e o poder deverá ser exercido de forma democrática, o que na opinião de Habermas só poderá ser efetivamente conquistado se houver um espaço público para discussão, onde estará assegurado o direito de participação na hermenêutica constitucional.

Habermas entende que num modelo de democracia procedimental a função do tribunal constitucional é manter o sistema de direitos que se fundamentada em possibilitar as condições efetivas para um procedimento discursivo de criação do direito que conjugue a autonomia pública e privada dos cidadãos, assegurando efetivamente os direitos fundamentais a todos.

A teoria discursiva não tem a pretensão de neutralidade, mas sim um ideal de imparcialidade que deverá ser atingido tendo como fio condutor a garantia da liberdade e igualdade na argumentação.

É preciso resgatar o conceito da democracia radical, e lutar para que haja um completo desenvolvimento da cidadania em nosso país. Atacando os problemas sociais através de políticas publicas efetivas, que tornem todos os cidadãos brasileiros, livres, autônomos e conscientes de seu papel, procurando atingir um ideal de justiça.

A participação cidadã pressupõe um processo de aprendizado por parte dos cidadãos de um estado democrático de direito. Ela precisa ser exercitada, não é nata, e como toda a aprendizagem também está sujeita a erros, o que não impede que este processo seja vivenciado por qualquer cidadão de um Estado democrático. 
Os cidadãos de um Estado devem buscar sua cidadania, num espaço que promova a discussão e onde haja reconhecimento recíproco de que todos devem fazer parte do processo democrático.

Será através do reconhecimento recíproco da cidadania, respeitando a esfera pública e privada de cada um, que os cidadãos poderão lidar com a complexidade das questões jurídicas apresentadas. Neste processo de aprendizagem os cidadãos encontram a legitimidade e efetividade tão importantes para o desenvolvimento do Estado democrático-constitucional de direito.

\section{REFERENCIAS}

ALEXY, Robert. Constitucionalismo Discursivo. 2. Ed. Porto Alegre: Livraria do Advogado, 2008.

ARAÚJO, Luiz Bernardo Leite Araújo. Liberalismo, Identidade e Reconhecimento em Habermas. Disponível em: http://revistaseletronicas.pucrs.br/ojs/index.php/veritas/article/viewFile/1864/1394. Acesso em: 14 jan. 2020.

ATHAYDE, Públio. Direito e Democracia em Habermas: Facticidade, Validade e Racionalidade. Disponível em: http://www.artigonal.com/doutrina-artigos/direito-edemocracia-em-habermans-faticidade-validade-e-racionalidade-674388.html. Acesso em: 11 jan.2020.

CANOTILHO, J.J. Gomes. Direito Constitucional e Teoria da Constituição. 7. Ed. Coimbra: Almedina, 2003.

CITTADINO, Gisele. Pluralismo, Direito e Justiça Distributiva. Rio de Janeiro: Lumen Juris, 2004

COUTINHO, Jacinto Nelson de Miranda( Org.). Canotilho e a Constituição Dirigente. 2. Ed. Rio de Janeiro: Renovar, 2005.

DUARTE, Ècio Oto Ramos Duarte. Teoria do Discurso e Correção Normativa do Direito. 2. Ed. São Paulo: Landy, 2004.

FISCHER, Octavio Campos; MACHADO, Luciano Marlon Ribas. Pacto Federativo em Crise: Uma Análise na Visão dos Municípios da Segurança Jurídica e da Dignidade Humana. Revista Juridica, [S.1.], v. 53, n. 4, p. 233 - 254, fev. 2020. ISSN 2316-753X. Disponível em: <http://revista.unicuritiba.edu.br/index.php/RevJur/article/view/3217/371371734>. Acesso em: 19 abr. 2020. doi:http://dx.doi.org/10.21902/revistajur.2316-753X.v53i4.3217. 
HAMERBAS, Jürgen. Direito e Democracia entre facticidade e validade I. 2. Ed. Rio de Janeiro: Biblioteca Tempo Universitário 101, 2003.

Comentários à Ética do Discurso. Lisboa: Instituto Piaget, 1991.

A Ética da Discussão e a Questão da Verdade. São Paulo: Martins Fontes, 2007.

SAAVEDRA, Giovani Agostini. Jurisdição e Democracia. Porto Alegre: Livraria do Advogado, 2006.

SIQUEIRA, Gustavo Silveira. A ação comunicativa para construção democrática e legitima do Estado de Direito. Disponível em: http://www.fafich.ufmg.br/compolitica/anais2007/sc_dc-gustavo.pdf. Acesso em: 11 jan. 2020.

STRECK, Lênio Luiz. Verdade e Consenso 3. Ed. Rio de Janeiro: Lumen Juris, 2009. 